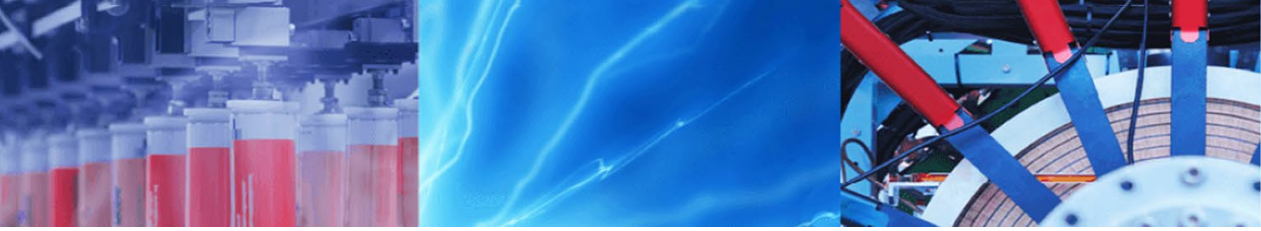

Research Article

\title{
Identification of degradation impurity of TGR5 receptor agonist-ZY12201 by LC-MS technique during force degradation study
}

\author{
Chandrakant Sojitra $^{1,2,3} \cdot$ Chintan Dholakia $^{1} \cdot$ Padmaja Sudhakar $^{2} \cdot$ Kumar K. Singh $^{1} \cdot$ Sameer Agarwal $^{3}$ D
}

Received: 14 January 2021 / Accepted: 13 May 2021

Published online: 25 May 2021

(c) The Author(s) $2021 \quad$ OPEN

\begin{abstract}
Forced degradation study is a systemic characterization of degradation products of active pharmaceutical ingredient (API) at conditions which posses more harsh environment that accelerates degradation of API. Forced degradation and stability studies would be useful in selection of proper, packaging material and storage conditions of the API. These are also useful to demonstrate degradation pathways and degradation products of the API and further characterisation of the degradation products using mass spectrometry. TGR5 is a G protein-coupled receptor, activation of which promotes secretion of glucagon-like peptide-1 (GLP-1) and modulates insulin secretion. The potent and orally bioavailable TGR5 agonist, ZY12201, shows activation of TGR5 which increase secretion of GLP-1 and help in lowering blood glucose level in animal models. Hence it is necessary to establish and study degradation pathway and stability of API for better handling and regulatory approval. Force degradation studies of ZY12201 have shown presence of one oxidative impurity during oxidative degradation in HPLC analysis. The oxidized product is further characterized by LC-MS to elucidate structure of impurity and characterize its degradation pathway.
\end{abstract}

Keywords LC-MS · TGR5 agonist · Force degradation study · Oxidized product · Stress testing

\section{Introduction}

Type 2 diabetes mellitus (T2DM) is a metabolic disorder sparked by insulin resistance and dysfunction of the $\beta$ cells. Type- 2 diabetes is generally characterized by increase in the resistant to insulin which leads to higher blood glucose level [1]. Impaired insulin sensitivity caused by malfunction of production, secretion and/or transport of insulin to an insulin receptors [2]. More recently, early studies have revealed that about $25 \%$ of people who went to the hospital with severe COVID-19 infections had diabetes. Those with diabetes mellitus were more likely to have serious complications and to die from the virus. One reason is that high blood sugar weakens the immune system and makes it less able to fight off infections [3]. Many drug substances like metformin, sulfonylurea class and different glinides [4] have been used to reverse the resistance of insulin in different organs, tissues and liver itself [5]. However, numbers of patients are not able to achieve glycemic control. Hence, there is a need for exploring

Dedicated in memory of chemistry teacher Late Shri Tilak Raj Taneja.

Supplementary Information The online version contains supplementary material available at https://doi.org/10.1007/s42452-021-04660y.

$\triangle$ Sameer Agarwal, sameeragarwal@zyduscadila.com | ${ }^{1}$ API Division, Cadila Healthcare Limited, Sarkhej-Bavla N.H. No. 8 A, Changodar, Ahmedabad 382 210, India. ${ }^{2}$ Department of Chemistry, Faculty of Science, M.S. University of Baroda, Baroda 390002 , India. ${ }^{3} Z$ ydus Research Centre, Cadila Healthcare Ltd., Sarkhej-Bavla N.H. No. 8 A, Moraiya, Ahmedabad 382 210, India.

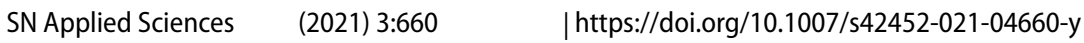


novel mechanism of action for the treatment of metabolic syndrome.

Bile acids plays a significance role in the emulsification lipids in the body and absorption of vitamins $A, D, E, K$ [6]. Along with these there is strong evidence that prove function of bile acid as signaling molecules in the endocrine system which regulated various metabolic activity and indirect glucose balance [7]. TGR5 (Takeda G-proteincoupled receptor 5 ) is a bile acid $G$ protein receptor which is also known as GPBAR1 [8]. We have reported the discovery of highly potent and orally efficacious TGR5 inhibitor, ZY12201 [9-11]. TGR5 receptors which is activated by bile salts are widely present in gallbladder, brain, liver, spleen and intestine [12]. TGR5 receptors are functions within tissue specific manner using increasing level of cyclic AMP present intraocular which leads to number of actions into body [13]. TGR5 receptors present at endocrine cells leads to release of glucagon like petide- 1 and peptide tyrosine inhibitor that helps to hunger satiety $[14,15]$. Thus, a novel TGR5 agonist may provide a treatment option for type 2 diabetes with simultaneous management of glucose levels, body weight, and associated complications. In addition, our group has also reported the effect of TGR5 agonist in combination with sitagliptin for the treatment of type-II diabetes[16]. Further we have also evaluated 2-mercapto imidazole and triazole derivatives as potential TGR5 agonist [17]. 2-((2-(4-(1H-imidazol-1-yl) phenoxy) ethyl) thio)-5-(2-(3,4-dimethoxyphenyl) propan-2-yl)-1-(4-fluoro phenyl)-1H-imidazole (ZY12201) (Fig. 1) is a potent, selective, and orally efficacious TGR5 agonist, having hTGR5 $\mathrm{EC}_{50}$ of $57 \mathrm{pM}$ and $\mathrm{mTGR} \mathrm{EC}_{50}$ of $62 \mathrm{pM}$ with a favorable pharmacokinetic properties and demonstrated in-vivo glucose lowering effects in animal models $\left(\mathrm{ED}_{50}\right.$ of $7.9 \mathrm{mg} /$ $\mathrm{kg}$ and $\mathrm{ED}_{90}$ of $29.2 \mathrm{mg} / \mathrm{kg}$ ) [10]. This work describes the possible degradation impurities and their characterization by force degradation study of ZY12201.

Abdelhameed et al. [18-20] have established the role of mass spectrometry in the identification and quantification of small concentration of drugs and its related impurities or metabolites. The formation of reactive metabolites

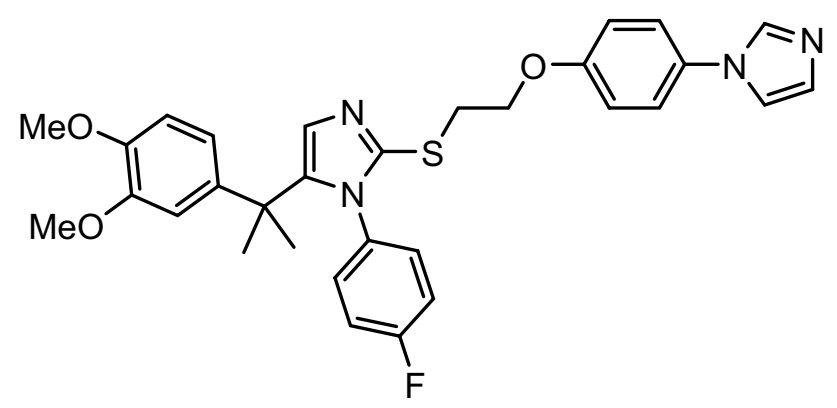

Fig. 1 Structure of ZY12201 during drug metabolism can result in the development of toxicities in different organs. Due to the unstable nature of reactive intermediates, capturing agents may be used which lead to the generation of stable adducts that can be extracted from the metabolic mixture and can be detected and characterized using liquid chromatography-tandem mass spectrometry (LC-MS/MS). Hence LC-MS can be proved as great tool for the identification of degradation impurities [21, 22].

\section{Experimental}

\subsection{Chemicals and reagents}

Standards and samples of ZY12201 were synthesized at Zydus Research Center, Cadila Healthcare Ltd. (Ahmedabad, India) $[10,11]$. HPLC grade acetonitrile and ammonia solution and analytical grade hydrochloric acid, sodium hydroxide, ammonium acetate, hydrogen peroxide solution (30\%) were purchased from Merck Specialties Pvt. Ltd. (Mumbai, India). High purity HPLC grade water was prepared by using Millipore Milli-Q plus water purification system, Bradford, PA, USA.

\subsection{Equipments and apparatus}

See Table 1.

\subsection{Preparation of sample solution for purity and stress studies}

Test solutions of ZY12201 with $1000 \mu \mathrm{g} / \mathrm{mL}$ concentration were prepared in diluents and further sonicated for $5 \mathrm{~min}$ to dissolve the compound, which were further analyzed by HPLC.

\subsection{HPLC chromatographic conditions}

A chromatography was performed on alliance waters separation module e2695 with YMC Triart C18 150 mm, $4.6 \mathrm{~mm}$ and $3 \mu \mathrm{m}$ particle size column using mobile phase includes, Solvent A $10 \mathrm{mM}$ ammonium acetate buffer $\mathrm{pH}$

Table 1 Equipment/instrument details

\begin{tabular}{ll}
\hline Equipment/instrument & Manufacture \\
\hline Waters HPLC-PDA system & Milford, MA, USA \\
Prominence Electrospray LC-MS system & Shimadzu, Japan \\
Analytical balance/ Micro balance & Mettler Toledo, USA \\
Sonicator & PCI Analytics, India \\
Photo stability chamber & Newtronic \\
\hline
\end{tabular}


Table 2 Gradient programme

\begin{tabular}{lll}
\hline Time & $\% \mathrm{~A}$ & $\% \mathrm{~B}$ \\
\hline 0.01 & 98 & 2 \\
3 & 98 & 2 \\
10 & 60 & 40 \\
20 & 60 & 40 \\
32 & 20 & 80 \\
40 & 20 & 80 \\
45 & 98 & 2 \\
50 & 98 & 2 \\
\hline
\end{tabular}

$(8.5 \pm 0.05)$ and solvent $B$ was mixture of $0.1 \%$ ammonia in acetonitrile with pump flow rate of $1.2 \mathrm{~mL} / \mathrm{min}$. The HPLC gradient mode ratios have been mentioned in Table 2 . The column temperature was maintained at $35^{\circ} \mathrm{C}$. Acetonitrile and water in the ratio of 95 to $5 \% \mathrm{v} / \mathrm{v}$ ratio was used as a diluent. Injection volume was $15 \mu \mathrm{L}$. Total run time was $50 \mathrm{~min}$. The retention time of ZY12201 and oxidative degraded product was $27.2 \mathrm{~min}$ and $18.5 \mathrm{~min}$ respectively. Detector wavelength was $228 \mathrm{~nm}$ and data processed using Empower 3 software; Version builds 3471.

\subsection{Optimized LC-MS method parameter}

An impurity obtained in the oxidation was further characterized and identified by LC-MS system. An electrospray LC-MS system (Shimadzu Prominence HPLC coupled with Triple Quadrupole Mass Spectrometer LCMS-8040 with lab solution software, version 5.72, Japan) was used for the identification of degradation impurities formed during stress testing studies. Chromatography was performed on YMC Triart C18 $150 \mathrm{~mm}, 4.6 \mathrm{~mm}$ and $3 \mu \mathrm{m}$ particle size column from YMC co. Ltd. Japan using mobile phase consisting of mobile phase $A(10 \mathrm{mM}$ ammonium acetate $(\mathrm{pH}$ 8.5) with ammonia solution) and mobile phase $B(0.1 \%$ ammonia in acetonitrile) at a flow rate of $1.2 \mathrm{~mL} / \mathrm{min}$. The LC gradient program was applied as per Table 2. The column temperature was maintained at $40^{\circ} \mathrm{C}$. Acetonitrilewater ratio of $95: 5 \%$, v/v was used as a diluent. Injection volume was $20 \mu \mathrm{L}$. The analysis was carried out by using electrospray ionization mode (+ve and -ve). The capillary voltage was at $3500 \mathrm{~V}$ and collision energy was $-35 \mathrm{~V}$. Desolvation temperature was $250^{\circ} \mathrm{C}$ with nebulizing gas flow rate $180 \mathrm{~L} / \mathrm{h}$.

\section{Force degradation study}

Forced degradation studies have been proved as an useful tool in analyzing stability of pharmaceutical products in different environmental conditions. Stability data and force degradation studies are very crucial for necessary regulatory aprovals [23]. Even $\mathrm{ICH}$ mandates to provide force degradation studies of new drug products along with information about potential degradants from force degradation $[24,25]$. As per ICH guidelines force degradation studies should be performed under different conditions of $\mathrm{pH}$, light, oxidation, dry heat, acidic, basic, hydrolysis etc. [26-28]. The FDA and ICH guidance mandate the requirement of forced degradation to recognize how the quality of a drug substance and drug product varies with time and different environmental factors $[29,30]$. The structural variety of drugs makes it very difficult for development of common force degradation set of protocol. The stress conditions applied should be related to the product's nature of decomposition [31]. The effects of chemical reactions can occurs with API are evaluated, mainly: hydrolysis of API can cause in increased humidity conditions, acidity or basicity and oxidation of API in the presence of reactive oxygen species, environmental oxygen or hydrogen peroxide, isomerization, hydration, dimerization are decarboxylation are performed to consider chemical stability of API. Photo stability tests are characterized by particular specificity and are an integral part of stability tests that are included in standard [30]. The selected approach must include products property along with details on its degradation under normal process of manufacturing, storage conditions and used conditions. Forced degradation factors necessarily include acid and base hydrolysis, thermal degradation, photolysis, and oxidation and may include freeze-thaw cycles and shear [32].

\section{Result and discussion}

\subsection{Force degradation results}

Chromatogram of the control sample for the reference in the degradation study has been given in Figure S-1.

\subsubsection{Result of acid degradation hydrolysis}

Test sample of $50 \mathrm{mg}$ weighed in $50 \mathrm{~mL}$ volumetric flask, added $2-3 \mathrm{~mL}$ of diluent to dissolve followed by $1 \mathrm{~mL}$ of $5.0 \mathrm{M}$ hydrochloric acid solution and heated at $60^{\circ} \mathrm{C}$ for $120 \mathrm{~min}$. Cool it at room temperature and neutralize the solution with $5.0 \mathrm{M}$ sodium hydroxide solution with help of $\mathrm{pH}$ paper. The chromatogram obtained from the sample after acidic hydrolysis reaction of ZY12201 has shown a satisfactory separation of compound and the degradation products (Figure S-2). 


\subsubsection{Result of alkali degradation}

Test sample of $50 \mathrm{mg}$ weighed in $50 \mathrm{~mL}$ volumetric flask, add $2-3 \mathrm{~mL}$ of diluent to dissolve then add $1 \mathrm{~mL}$ of $5.0 \mathrm{M}$ sodium hydroxide solution and heated at $60^{\circ} \mathrm{C}$ for $120 \mathrm{~min}$. Cool it at room temperature and neutralize the solution with $5.0 \mathrm{M}$ hydrochloric acid solution with help of $\mathrm{pH}$ paper. The chromatogram for the alkali treated ZY12201 sample was achieved satisfactory (Figure S-3).

\subsubsection{Result of oxidative degradation}

Hydrogen peroxide has been used for the oxidative stress degradation. Electron transfer serves as basic mechanism for the oxidative forced degradation of drug substance [33]. ZY12201 sample was treated with $1 \mathrm{~mL}$ of 3\% hydrogen peroxide solution and kept at room temperature for $4 \mathrm{~h}$. Chromatographic separation of formed oxidized degradation product was achieved (Figure S-4).

\subsubsection{Results of photo degradation}

ICH guidelines have recommended the conditions protocols for photo stability studies [34]. Accordingly, ZY12201 samples were exposed to a minimum light of 1.2 million lux $\mathrm{h}$ and $200 \mathrm{Wh} / \mathrm{m}^{2}$ light; $300-800 \mathrm{~nm}$ wavelengths are commonly used to cause the photolytic degradation [35]. Free radical mechanism was proposed for photolytic degradation. Carbonyls, nitro aromatic, $\mathrm{N}$-oxide, alkenes, aryl chlorides, weak $\mathrm{C}-\mathrm{H}$ and $\mathrm{O}-\mathrm{H}$ bonds, sulfides and polyenes are example of photosensitive groups present in pharmaceuticals [36]. ZY12201 sample was exposed for UV degradation under a photo stability chamber (Model: NLPS4SI) for 7 days. However, no significant degradation in product was observed with UV exposure (Figure S-5).

\subsubsection{Result of thermal degradation}

Sample was exposed at $105^{\circ} \mathrm{C}$ for $24 \mathrm{~h}$ to study the thermal decomposition or thermolysis caused by heat [37]. HPLC chromatogram for thermal treated ZY12201 sample is shown in Figure S-6. Results of peak purity is shown in Table 3.

\subsubsection{Summary of force degradation study}

Force degradation studies have concluded that there was no significant changes have been found during the degradation study except oxidative degradation. Summary of force degradation study has been shown in Table 3.

\subsection{Peak purity results}

Peak purity is a comparison of the reference standard to the API in the sample stressed by forced degradation to confirm that no impurity is eluted. Peak threshold is used as a parameter for determining peak purity in HPLC. For the acceptance of the peak purity, angle should be less than a purity threshold. Peak purity results are summarized in Table 4.

\subsection{Identification of impurity by LC-MS}

Identification of degradation related impurities for ZY12201 was done in oxidation treated sample through

Table 3 Force degradation summary

\begin{tabular}{lllllll}
\hline Degradation condition & Time & Temp & Assay (\%,w/w) & $\begin{array}{l}\text { Degra- } \\
\text { dation } \\
(\% \mathrm{w} / \mathrm{w})\end{array}$ & $\begin{array}{l}\text { Mass balance (\% } \\
\text { assay+\% deg. prod- } \\
\text { ucts) }\end{array}$ & Remarks/observation \\
\hline A control sample (untreated) & - & - & 96.4 & 2.8 & 99.2 & $\mathrm{NA}$ \\
$\mathrm{HCl}, 5.0 \mathrm{~N}$ (acid degradation) & $2 \mathrm{~h}$ & $60^{\circ} \mathrm{C}$ & 95.0 & 3.5 & 98.5 & No significant degradation observed \\
$\mathrm{NaOH}, 5.0 \mathrm{~N}$ (base degradation) & $2 \mathrm{~h}$ & $60^{\circ} \mathrm{C}$ & 93.1 & 4.1 & 97.2 & No significant degradation observed \\
Oxidation by 3.0\% $\mathrm{H} 2 \mathrm{O} 2$ & $2 \mathrm{~h}$ & $25^{\circ} \mathrm{C}$ & 79.3 & 21.02 & 100.3 & Oxidized product was formed \\
Thermally treated & $24 \mathrm{~h}$ & $105^{\circ} \mathrm{C}$ & 97.1 & 2.8 & 99.9 & No significant degradation observed \\
UV treated $(254 \mathrm{~nm})$ & $24 \mathrm{~h}$ & $25^{\circ} \mathrm{C}$ & 96.9 & 2.75 & 99.7 & No significant degradation observed \\
\hline
\end{tabular}

Table 4 Peak purity results

\begin{tabular}{llllll}
\hline Degradation condition & Acid treated & Alkali treated & $\begin{array}{l}\text { Oxidation } \\
\text { treated }\end{array}$ & $\begin{array}{l}\text { Photolytic } \\
\text { treated }\end{array}$ & Thermal treated \\
\hline Purity angle & 3.467 & 3.557 & 0.702 & 1.855 & 1.512 \\
Purity threshold & 5.716 & 5.390 & 1.344 & 3.001 & 2.450 \\
\hline
\end{tabular}


Table 5 ZY12201 and its oxidation degraded impurities mass value

\begin{tabular}{ll}
\hline Retention time $(\mathrm{min})$ & Mass value $\left(\mathrm{M}^{+}\right)$ \\
\hline 13.57 & 284.10 \\
19.63 (identified impurity) & 575.25 \\
21.95 & 417.20 \\
22.45 & 593.30 \\
25.91 & 536.30 \\
27.09 & 508.25 \\
27.88 (ZY12201) & 559.25 \\
28.70 & 575.25 \\
31.57 & 522.25 \\
\hline
\end{tabular}

LC-MS technique. Total eight impurities were formed during oxidation degradation, among all impurity in ZY12201 oxidation treated sample, one impurity was confirmed and identified through mass spectral analysis. The degraded impurities mass and retention time has been reported in Table 5 and mass spectra of all impurities are shown in Figure S-7.

The positive ion mass spectral analysis of impurity-1 was observed at $575\left(\mathrm{M}^{+}\right)$suggesting the possibility of Molecular formula $\mathrm{C}_{31} \mathrm{H}_{31} \mathrm{FN}_{4} \mathrm{O}_{4} \mathrm{~S}$, which confirms the theoretical molecular weight of Impurity-1.

\section{Oxidative degradation pathway}

Form the above mentioned degradation study it was demonstrated tht in the presence of oxidizing agent ZY12201 has been degraded to its related substance. Thus, the degradation pathway has been confirmed with help of LC-MS system which is shown in Sect. 4.3. Figure 2 shows the degradation pathway of compound ZY12201 in presence of oxidizing agent like hydrogen peroxide.

\section{Conclusion}

The developed liquid chromatography method is a rapid, precise, selective and capable for separation of ZY12201 from its degradation products with good resolution. Additioanlly, this method can be used for routine testing and stability analysis in quality control laboratories to check purity of ZY12201 in bulk and pharmaceutical formulation. The product must be packed in air tight container with nitrogen packing for stability studies and transportation purpose.
Fig. 2 Oxidation degradation pathway of ZY12201
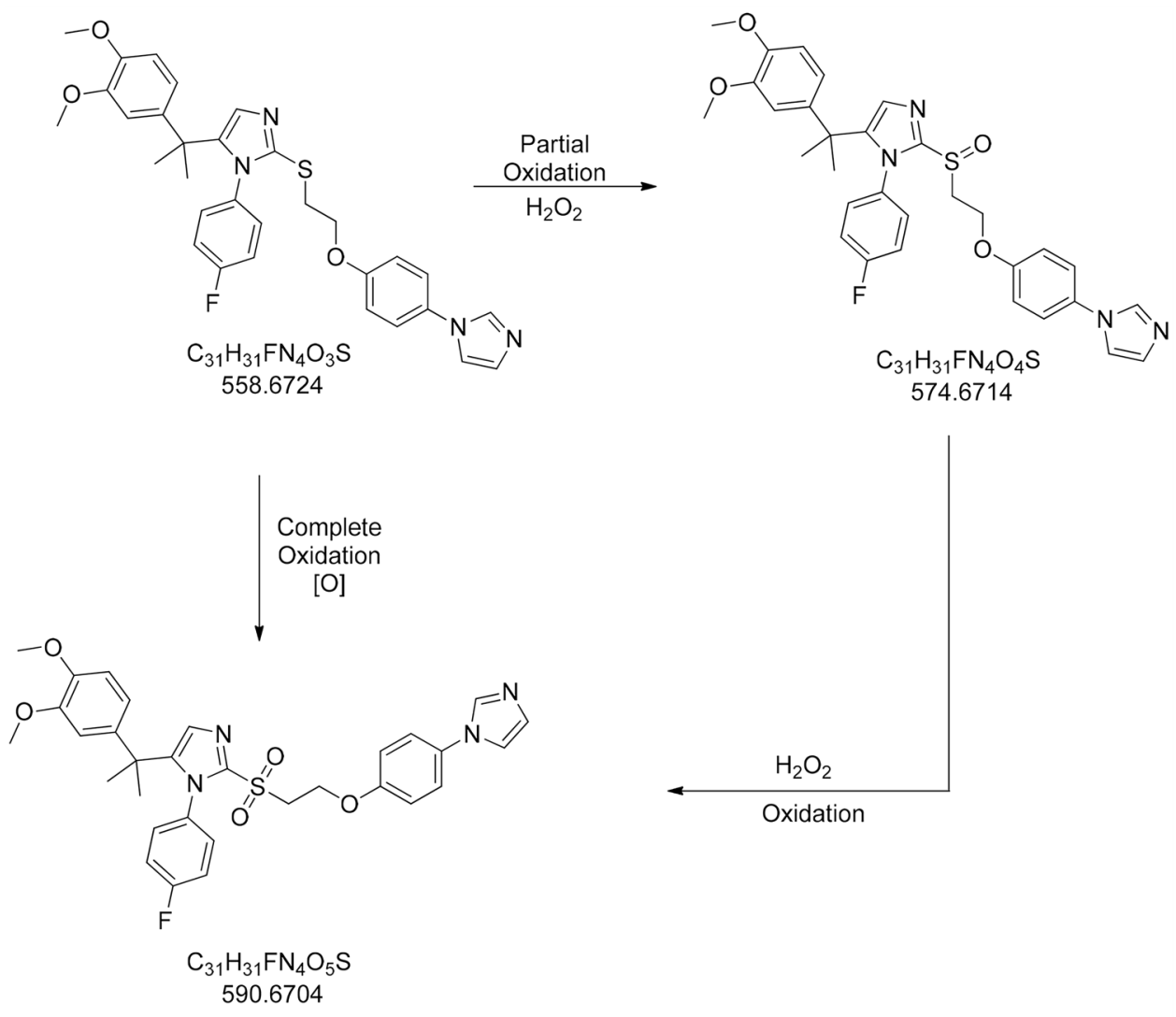

SN Applied Sciences 
Acknowledgements The authors would like to acknowledge the management of Cadila Healthcare Ltd. for support and encouragement. ZRC Communication No.658.

\section{Declarations}

Conflict of interest The authors declare that they have no conflict of interest.

Open Access This article is licensed under a Creative Commons Attribution 4.0 International License, which permits use, sharing, adaptation, distribution and reproduction in any medium or format, as long as you give appropriate credit to the original author(s) and the source, provide a link to the Creative Commons licence, and indicate if changes were made. The images or other third party material in this article are included in the article's Creative Commons licence, unless indicated otherwise in a credit line to the material. If material is not included in the article's Creative Commons licence and your intended use is not permitted by statutory regulation or exceeds the permitted use, you will need to obtain permission directly from the copyright holder. To view a copy of this licence, visit http://creativecommons. org/licenses/by/4.0/.

\section{References}

1. Yang Y, Hu X, Zhang Q, Zou R (2016) Diabetes mellitus and risk of falls in older adults: a systematic review and meta-analysis. Age Ageing 45(6):761-767

2. Henquin J-C (2000) Triggering and amplifying pathways of regulation of insulin secretion by glucose. Diabetes 49(11):1751-1760

3. Lim S, Bae JH, Kwon HS et al (2021) COVID-19 and diabetes mellitus: from pathophysiology to clinical management. Nat Rev Endocrinol 17:11-30

4. Ashiya M, Smith RE (2007) Non-insulin therapies for type 2 diabetes. Nat Rev Drug Discov 6:777-778

5. Rotella CM, Pala L, Mannucci E (2013) Role of insulin in the type 2 diabetes therapy: past, present and future. Int J Endocrinol Metab 11(3):137

6. Baptissart M, Vega A, Maqdasy S, Caira F, Baron S, Lobaccaro J-MA, Volle DH (2013) Bile acids: from digestion to cancers. Biochimie 95(3):504-517

7. Schaap FG, Trauner M, Jansen PL (2014) Bile acid receptors as targets for drug development. Nat Rev Gastroenterol Hepatol 11(1):55

8. Sato $\mathrm{H}$, Genet $\mathrm{C}$, Strehle A, Thomas C, Lobstein A, Wagner A, Mioskowski C, Auwerx J, Saladin R (2007) Anti-hyperglycemic activity of a TGR5 agonist isolated from Olea europaea. Biochem Biophys Res Commun 362(4):793-798

9. Joshi VM, Sojitra C, Sasane S, Shukla M, Chauhan R, Chaubey V, Jain S, Shah K, Mande HM, Soman SS (2020) Practical and efficient synthesis of 2-thio-imidazole derivative-ZY12201: a potent TGR5 agonist. Org Process Res Dev 8:1508-1514

10. Agarwal S, Patil A, Aware U, Deshmukh P, Darji B, Sasane S, Sairam KV, Priyadarsiny P, Giri P, Patel H (2016) Discovery of a potent and orally efficacious TGR5 receptor agonist. ACS Med Chem Lett 7(1):51-55

11. Agarwal S, Jain MR, Patel PR (2013) 2-Thio-imidazole derivatives as TGR5 modulators. PCT Int Appl WO 2013/054338, 18 April 2013 (Appl. PCT/IN2012/000471, 4.07.2012)

12. Maruyama T, Miyamoto $Y$, Nakamura T, Tamai $Y$, Okada $H$, Sugiyama E, Nakamura T, Itadani H, Tanaka K (2002) Identification of membrane-type receptor for bile acids (M-BAR). Biochem Biophys Res Commun 298(5):714-719
13. Hannah M (2014) TGR5 ligands as potential therapeutics in inflammatory diseases. Int J Interferon Cytokine Mediator Res 6:27-38

14. Thomas C, Gioiello A, Noriega L, Strehle A, Oury J, Rizzo G, Macchiarulo A, Yamamoto H, Mataki C, Pruzanski M (2009) TGR5mediated bile acid sensing controls glucose homeostasis. Cell Metab 10(3):167-177

15. Bala V, Rajagopal S, Kumar DP, Nalli AD, Mahavadi S, Sanyal AJ, Grider JR, Murthy K (2014) Release of GLP-1 and PYY in response to the activation of $G$ protein-coupled bile acid receptor TGR5 is mediated by Epac/PLC- $\varepsilon$ pathway and modulated by endogenous H2S. Front Physiol 5:420

16. Agarwal S, Sasane S, Kumar J, Deshmukh P, Bhayani H, Giri P, Giri S, Soman S, Kulkarni N, Jain M (2018) Evaluation of novel TGR5 agonist in combination with Sitagliptin for possible treatment of type 2 diabetes. Bioorg Med Chem Lett 28(10):1849-1852

17. Agarwal S, Sasane S, Kumar J, Darji B, Bhayani H, Soman S, Kulkarni N, Jain M (2019) Novel 2-mercapto imidazole and triazole derivatives as potent TGR5 receptor agonists. Med Drug Discov 1:100002

18. Kadi AA, Angawi RF, Attwa MW, Darwish HW, Abdelhameed AS (2013) High throughput quantitative bioanalytical LC/MS/ MS determination of gemifloxacin in human urine. J Chem 2013:905704

19. Attwa Mohamed W, Kadi AA, Darwish HW, Abdelhameed AS (2018) Investigation of the metabolic stability of olmutinib by validated LC-MS/MS: quantification in human plasma. RSC Adv 8(70):40387-40394

20. Kadi AA et al (2016) Liquid chromatographic-tandem mass spectrometric assay for simultaneous quantitation of tofacitinib, cabozantinib and afatinib in human plasma and urine. Trop J Pharm Res 15(12):2683-2692

21. Attwa MW, Kadi AA, Abdelhameed AS (2020) Detection and characterization of olmutinib reactive metabolites by LC-MS/MS: elucidation of bioactivation pathways. J Sep Sci 43(4):708-718

22. Attwa MW, Kadi AA, Abdelhameed AS (2020) Phase I metabolic profiling and unexpected reactive metabolites in human liver microsome incubations of X-376 using LC-MS/MS: bioactivation pathway elucidation and in silico toxicity studies of its metabolites. RSC Adv 10(9):5412-5427

23. Guideline IHT (1996) Photostability testing of new drug substances and products Q1B, current step 4:1-12

24. Reynolds DW, Facchine KL, Mullaney JF, Alsante KM, Hatajik TD, Motto MG (2002) Conducting forced degradation studies. Pharm Technol 26:48-56

25. Bajaj S, Singla D, Sakhuja N (2012) Stability testing of pharmaceutical products. J App Pharm Sci 2(3):129-138

26. Guideline IHT (2003) Evaluation for stability data Q1E, current step 4:1-19

27. Waterman KC, Adami RC (2005) Accelerated aging: prediction of chemical stability of pharmaceuticals. Int J Pharm 293(1-2):101-125

28. Guideline IHT (2003) Stability testing of new drug substances and products $Q 1 A(R 2)$, current step 4:1-24

29. Guideline IHT (2005) Validation of analytical procedure: text and methodology Q2(R1), current step 4:1-17

30. Guideline IHT (2006) Impurities in new drug products. Q3B (R2), current step 4:1-16

31. Singh R (2012) Current trends in forced degradation study for pharmaceutical product development. J Pharm Educ Res 3(1):324

32. Ali NW, Abbas SS, Zaazaa HE-S, Abdelrahman MM, Abdelkawy M (2012) Validated stability indicating methods for determination of nitazoxanide in presence of its degradation products. J Pharm Anal 2(2):105-116 
33. Annapurna MM, Mohapatro C, Narendra A (2012) Stabilityindicating liquid chromatographic method for the determination of Letrozole in pharmaceutical formulations. J Pharm Anal 2(4):298-305

34. Kats M (2005) Forced degradation studies: regulatory considerations and implementation. BioPharm Int 18(7):40-45

35. Alsante KM, Ando A, Brown R, Ensing J, Hatajik TD, Kong W, Tsuda $Y$ (2007) The role of degradant profiling in active pharmaceutical ingredients and drug products. Adv Drug Deliv Rev 59(1):29-37

36. Gupta A, Yadav JS, Rawat S, Gandhi M (2011) Method development and hydrolytic degradation study of Doxofylline by RP HPLC and LC-MS/MS. Asian J Pharm Anal 1:14-18
37. Iram F, Iram H, Iqbal A, Husain A (2016) Forced degradation studies. J Anal Pharm Res 3(6):00073

Publisher's Note Springer Nature remains neutral with regard to jurisdictional claims in published maps and institutional affiliations. 